\title{
Molecular identification of a Heterorhabditis entomopathogenic nematode isolated from the northernmost region of South Africa
}

\author{
Tshikala Eddie Lulamba and Mahloro Hope Serepa-Dlamini* (D)
}

\begin{abstract}
Entomopathogenic nematodes (EPNs) are among the frequently used and commercialized bio-pesticides. However, they are restricted in their infectivity, persistence, storage, and cost of production. One of the methods used to improve this is a continuous search for new isolates with significant behavioral and physiological characteristics. A novel EPN isolate, Heterorhabditis zealandica strain ETL, isolated from South Africa (GPS co-ordinates - 24.849721 and 28.336980) is described and studied against late-instar of Galleria mellonella (L.) and Tenebrio mollitor (L.) larvae. The morphological and molecular studies indicated this isolate as a Heterorhabditis strain. The comparison of sequences of the internal transcribed spacer (ITS) region, the 185 rRNA gene, and the D2-D3 region of the 285 rRNA gene with available sequences of other described species within the genus indicate the isolate as a new Heterorhabditis zealandica strain. The phylogenetic analysis of the sequence data places strain ETL, closest to H. zealandica strain Bartow (GU174009) in the Heterorhabditis group. This EPN was lethal to G. mellonella and T. mollitor; as infections occurred within 24-96 h. Fifty percent of the larvae population were killed within $24 \mathrm{~h}$ and $100 \%$ after $96 \mathrm{~h}$.
\end{abstract}

Keywords: Entomopathogenic nematodes, Heterorhabditis zealandica strain ETL, Molecular identification, South Africa

\section{Background}

Entomopathogenic nematodes (EPNs) are highly pathogenic to numerous insect pests (Malan and Ferreira 2017). Effective biocontrol agents of insects have been mainly isolated from the genera Steinernema and Heterorhabditis, which are mutually associated with bacteria of the genera Xenorhabdus and Photorhabdus, respectively (Malan and Ferreira 2017). Recently, Oscheius EPN genus associated with symbiotic bacteria of Serratia genus was reported (Torres-Barragan et al. 2011). To date, EPNs are used and commercialized as bio-control agents of insect pests in large-scale agricultural and individual home gardens in many countries (Azazy et al. 2018). South Africa (SA) demonstrates a rich EPN fauna with biocontrol potential (Hatting and Malan 2017). Few

\footnotetext{
*Correspondence: hopes@uj.ac.za

Department of Biotechnology and Food Technology, Faculty of Science, University of Johannesburg, Doornfontein Campus, PO Box 17011 Doornfontein, Johannesburg 2028, South Africa
}

data on the diversity and activity of EPNs from different provinces of SA are available.

The EPN characterization is particularly useful to (1) match the appropriate EPN species with a targeted pest (or environmental conditions) for an effective biocontrol potential and/or integrated pest management (IPM) programs (Peat et al. 2009), (2) to prevent the importation of species (and/or strains) that can outcompete native species and compromise the local biodiversity, and (3) to select species with beneficial properties for commercial bio-prospecting purposes, such as the use of patents or other legal issues (Peat et al. 2009). Therefore, identifying the EPN species accurately is critical.

The initial morphological characterization of the EPN taxonomy is difficult because of the relatively conservative morphological traits of nematodes (Peat et al. 2009). Molecular systematics, compounded by the improvement of both polymerase chain reaction (PCR) and DNA sequencing techniques, have proven adequate and
Springer Open (c) The Author(s). 2020 Open Access This article is licensed under a Creative Commons Attribution 4.0 International License, which permits use, sharing, adaptation, distribution and reproduction in any medium or format, as long as you give appropriate credit to the original author(s) and the source, provide a link to the Creative Commons licence, and indicate if changes were made. The images or other third party material in this article are included in the article's Creative Commons licence, unless indicated otherwise in a credit line to the material. If material is not included in the article's Creative Commons licence and your intended use is not permitted by statutory regulation or exceeds the permitted use, you will need to obtain permission directly from the copyright holder. To view a copy of this licence, visit http://creativecommons.org/licenses/by/4.0/. 
played a key role in advancing the EPN taxonomy, which contributed to the expansion of knowledge on EPN biodiversity, geographic distributions, host ranges, ecology, behavior, and co-evolution (Peat et al. 2009). Molecular characters are considered as the most suitable approach for species identification and systematics of nematodes, especially for taxonomic ambiguities, identification of members of a species complex, and the differentiation of morphologically similar species (Peat et al. 2009). Thus, they have been widely used (Peat et al. 2009; CamposHerrera 2015).

Sequence data from nuclear and mitochondrial genetic loci, and whole genomes (more recently) are used in EPNs studies, as well as nuclear ribosomal DNA (rDNA) genes, partial messenger RNA (mRNA) copies of protein-coding genes (expressed sequence tags (ESTs)) are used to infer the phylogenetic relationship (Peat et al. 2009). Among these, nuclear genes have been used extensively; each has numerous copies and evolves at different rates. Their variable and conserved regions render it possible to differentiate taxonomic levels and delimitate the nematode taxa (Stock 2009). They include the external non-transcribed spacer (NTS); the small subunit (SSU) or 18S; the internal transcribed spacer (ITS) region that separates rDNA-coding regions (Adams et al. 2006) composed of ITS-1, 5.8S, and ITS-2; and the large subunit (LSU) or $28 S$ (Stock 2009).

The rRNA gene sequences can vary in length and nucleotide composition, insertion, and deletion events, sometimes involving blocks of multiple nucleotides occur frequently (ITS sequence length differences of > 100 bp can be observed), and can result in rDNA size differences between sequences (Peat et al. 2009). These, unlike protein-coding genes, do not compromise the function of the ribosome (Nguyen et al. 2001), but can render dubious the homological position of characters (useful for delimitating species) during the phylogenetic reconstruction (Peat et al. 2009). Thus, inaccurate tests of homology statements during alignment, compounded by a high number of taxa (which drastically increases the number of possible phylogenetic solutions) can lead to spurious phylogenies (Peat et al. 2009). The aim of this study was to isolate and identify a native EPN species that can be suitable as a biocontrol agent by testing it against Galleria mellonella L. and Tenebrio mollitor L. larvae under laboratory conditions.

\section{Materials and methods}

\section{Soil sampling and isolation of entomopathogenic nematodes}

Eighty-seven soil samples were collected from both agricultural disturbed and natural undisturbed soils from the locality of Bela-Bela in Limpopo province of South Africa according to the method of Kaya and Stock
(1997). Accordingly, samples were taken from a depth of up to $20 \mathrm{~cm}$ and placed in plastic containers $(2000 \mathrm{ml})$ with lids and transported to the laboratory for processing. In the laboratory, isolation of EPNs from soil samples was performed, following the live bait method-using laboratory-reared late-instar larvae of the greater wax moth, Galleria mellonella L. (Bedding and Akhurst 1975). Briefly, after adjusting the soil humidity to about $10 \%$ using sterilized water (to encourage the potential EPNs movements) (Ruan et al. 2018), 10 late-instar larvae were placed in each container, and the container was inverted. The containers were incubated at room temperature $\left( \pm 25^{\circ} \mathrm{C}\right)$ and checked daily for larval infection and death based on color change. Dead larvae were collected and cultured according to the White-trap method (White 1927). Infective juveniles (IJs) emerging from the cadavers of G. mellonella were collected from the White-traps and used for re-infecting fresh larvae to ensure the maintenance of the nematode's population, and some of the IJs were used for the subsequent determination of the pathogenicity against G. mellonella and T. mollitor larvae. The most virulent isolate (isolated from GPS co-ordinates - 24.849721 and 28.336980 ) was selected for subsequent analyses.

\section{EPN pathogenicity test}

Nematode initial pathogenicity was evaluated according to Glazer and Lewis (2000), using late instar of G. mellonella and T. mollitor larvae in a Petri dish with $10-\mathrm{cm}$ diameter lined with 2 layers of moist filter paper (Whatman No. 1). Accordingly, each Petri dish contained $10 \mathrm{~g}$ of sterile sandy loam soil, four live larvae, and approximately 250 of IJs, and control dishes had only distilled water instead of IJs. The Petri dishes were incubated at $25{ }^{\circ} \mathrm{C}$ in the dark and observed daily for mortality of the larvae for $96 \mathrm{~h}$. Dead larvae were collected daily and placed on White-traps for collection of emerging IJs. The experiment was conducted in quintuplets and repeated 4 times.

\section{Morphological characterization of EPN}

An initial morphological characterization of EPN IJs (Stock and Hunt 2005) was done using a scanning electron microscope (SEM). Accordingly, IJs and 1st-generation adults (males, hermaphrodite, and/or amphimictic females) were heat-killed at $60^{\circ} \mathrm{C}$ for $2 \mathrm{~min}$ in Ringer's solution. Infective juveniles were rinsed with Ringer's solution 3 times with a 5 -min interval between each rinse. These were then fixed in 8\% glutaraldehyde overnight (glutaraldehyde 25\% EM grade, diluted in Ringers' solution). For post fixing, these were rinsed by sterile distilled water 3 times and dehydrated with $30,50,70,90,95$, and $100 \%$ ethanol at 10 min intervals. These were then critically point dried with $\mathrm{CO}_{2}$ for $2 \mathrm{~h}$ and mounted on SEM stubs, coated with gold and 
palladium, and viewed using TESCAN VEGA3 microscope (TESCAN ORSAY HOLDING, a.s., Brno - Kohoutovice, Czech Republic).

\section{Molecular characterization of EPN Amplification and sequencing}

The EPNs were inbred 13 times to eliminate heterozygosity and the total genomic DNA extracted. Protocol from ISOLATE II Genomic DNA Kit (Bioline USA Inc., 305 Constitution Drive, Taunton, MA, 02780, USA) was followed to extract and purify the total genomic DNA. To identify the EPN, $18 \mathrm{~S}$ rRNA gene, internal transcribed spacer (ITS) region, and the D2-D3 region on the $28 \mathrm{~S}$ rRNA gene were used (Nguyen and Hunt 2007). The ITS region was amplified using universal primers TW81 and AB28 (Joyce et al. 1994), $18 S$ rRNA gene using primers (18S-26S) by Subbotin et al. (2006) and primers (D2AD3B) described by Vovlas et al. (2006) were used for D2D3 region on the $28 S$ rRNA gene. The PCR solution had a final volume of $25 \mu \mathrm{l}$, including $12.5 \mu \mathrm{l}$ of $2 \times$ PCR Master Mix, $4 \mu \mathrm{l}$ genomic DNA, $3 \mu \mathrm{l}$ of each primer with $10 \mu \mathrm{M}$ concentration, and $2.5 \mu \mathrm{l}$ of nuclease-free water. The PCR reactions were conducted using a Bio-Rad $\mathrm{T}_{100}{ }^{\text {tx }}$ Thermal Cycler, (Bio-Rad Laboratories, Inc., Hercules, California 94547, USA). This consisted of an initial denaturation at $94{ }^{\circ} \mathrm{C}$ for $4 \mathrm{~min}$, followed by 35 cycles of $94{ }^{\circ} \mathrm{C}$ for $1 \mathrm{~min}$, $50-55^{\circ} \mathrm{C}$ for $30 \mathrm{~s}$, and $72^{\circ} \mathrm{C}$ for $2 \mathrm{~min}$; and a final extension at $72^{\circ} \mathrm{C}$ for $10 \mathrm{~min}$. The PCR product was electrophoresed at $80 \mathrm{~V}$ for about $30 \mathrm{~min}$ on agarose gel $(1 \% \mathrm{v} / \mathrm{v}$ : agarose/1X TBE [Tris base, boric acid and EDTA]) buffer stained with ethidium bromide (EtBr). PCR products were purified and concentrated using the QIAquick PCR Purification kit before sending for sequencing at a commercial service provider, Inqaba Biotechnical Industries (Pty) Ltd., Pretoria, South Africa.

\section{Phylogenetic analysis of the EPNs}

BioEdit v 7.2 (Hall 2005) software was used for editing and creating the consensus sequences. The consensus DNA sequences for each marker were searched against the NCBI (National Center for Biotechnology Information) nucleotide collection database, using BLAST (Basic Local Alignment Search Tool) for closely related species with high similarity percentages as well as low $e$ values. All phylogenetic analyses post-BLAST were performed in MEGA 7 (Kumar et al. 2016). The selected species from the BLAST search and present isolates in the study were aligned, using MUSCLE (MUltiple Sequence Comparison by Log-Expectation) (Edgar 2004). Maximum likelihood trees of the homologous sequences obtained were inferred with 1000 replications, using the JukesCantor model (Jukes and Cantor 1969). Bootstrap analysis with 1000 replicates was used to determine branch support (Nguyen and Hunt 2007).

\section{Statistical analysis}

The EPN pathogenicity method was statistically validated by a one-way analysis of variance (ANOVA) using IBM SPSS Statistics 22 (SPSS/IBM, Chicago, IL, USA). Mean values of the number of dead G. mellonella and T. mollitor larvae recorded daily post-EPN application were compared. Significant differences at $p \leq 0.05$ level of probability were reported.

\section{Results and discussion \\ Isolation and characterization of EPNs Isolation and morphological characterization}

EPNs were isolated in four samples (5\%). Of the 4 samples, only one sample displayed complete virulence against the larvae allowing subsequent IJ production for further study. Although this represents a low recovery, this study highlights the need for more EPN surveys and studies in the northern parts of SA. From the scanning electron microscope, the isolated IJ had similar characters as those described by Stock and Hunt (2005) within the family Heterorhabditidae. Accordingly, the cuticle had longitudinal ridges throughout most of its body length and a tessellate pattern in the anterior-most region, lateral field with 2 ridges, head with prominent $\mathrm{cu}$ ticular dorsal tooth, excretory pore located posterior to the basal bulb, and tail short, conoid and tapering to a small spike-like tip (Additional file 1: Figure S1).

\section{Molecular characterization}

The sequences of the ITS, $18 S$ rRNA gene, and the D2-D3 region of the $28 S$ rRNA gene were analyzed. The BLAST analysis of the ITS consensus gene $(819 \mathrm{bp})$ attributed 99.88 and $99 \%$ of the similarities and query coverage with both $H$. zealandica strain Bartow (GU174009) and $H$. zealandica isolate WS20 (KY055373), and 99.51 and 99\% of similarities and query coverage with both $H$. zealandica strain NZH3 (EF530041) and H. zealandica (AY32148) (Table 1). The $28 S$ consensus gene $(614 \mathrm{bp})$ attributed a $100 \%$ of both similarities and query coverage with $\mathrm{H}$. zealandica strain WS5 (KY021160), H. zealandica (EU099035), and H. zealandica (AM039761); and 99.84\% of similarities and $100 \%$ query coverage with $H$. zealandica strain Bartow (GU177843); and 99.67\% of similarities and $100 \%$ query coverage with strain Cohen 32 (GU177844). Finally, the $18 S$ gene (515 bp) showed $100 \%$ of similarity and $99 \%$ query coverage with Heterorhabditis sp. EPNKU59 (MG742141), Heterorhabditis sp. EPNKU54 (MG742139), Heterorhabditis sp. EPNKU52 (MG742137), Heterorhabditis sp. EPNKU42 (MG742133), Heterorhabditis sp. EPNKU18 (MG742131), Heterorhabditis sp. EPNKU39 (MG742154), Heterorhabditis sp. EPNKU31 (MG742152), Heterorhabditis sp. EPNKU30 (MG742151), Heterorhabditis sp. EPNKU26 (MG742149), Heterorhabditis sp. EPNKU25 (MG742148), Heterorhabditis sp. 
Table 1 The BLAST results including three significant hits for each molecular marker used in the study for Heterorhabditis zealandica strain ETL

\begin{tabular}{|c|c|c|c|c|c|c|}
\hline \multirow{2}{*}{$\begin{array}{l}\text { Heterorhabditis spp./strain } \\
\text { Description }\end{array}$} & \multicolumn{6}{|c|}{ Blast statistics } \\
\hline & Max. score & Total score & Query cover (\%) & $e$ value & Per. identity (\%) & Accession \\
\hline \multicolumn{7}{|l|}{ Internal transcribed spacer (ITS) } \\
\hline Heterorhabditis zealandica strain Bartow & 1507 & 1507 & 99 & 0.0 & 99.88 & GU174009.1 \\
\hline H. zealandica strain WS20 & 1495 & 1495 & 99 & 0.0 & 99.88 & KY055373.1 \\
\hline H. zealandica strain NZH3 & 1491 & 1491 & 99 & 0.0 & 99.51 & EF530041.1 \\
\hline \multicolumn{7}{|l|}{285} \\
\hline H. zealandica isolate WS5 & 1134 & 1134 & 100 & 0.0 & 100 & KY021160.1 \\
\hline H. zealandica & 1134 & 1134 & 100 & 0.0 & 100 & EU099035.1 \\
\hline H. zealandica & 1134 & 1134 & 100 & 0.0 & 100 & AM039761.1 \\
\hline \multicolumn{7}{|l|}{185} \\
\hline H. sp. EPNKU59 & 948 & 948 & 99 & 0.0 & 100 & MG742141.1 \\
\hline H. sp.EPNKU54 & 948 & 948 & 99 & 0.0 & 100 & MG742139.1 \\
\hline H. sp.EPNKU52 & 948 & 948 & 99 & 0.0 & 100 & MG742137.1 \\
\hline
\end{tabular}

EPNKU22 (MG742147), and $H$. indica isolate DH2 (MK273195). These strains were isolated from Thailand. The name Heterorhabditis zealandica strain ETL was assigned to the isolate, and the consensus sequences were submitted to NCBI-GenBank database and accession numbers MH443371 (for ITS), MH443381 (for D2-D3 region on $28 S$ rRNA gene), and MN341010 (18S rRNA gene) were assigned.

The evolutionary history was inferred by using the maximum likelihood method, using Jukes-Cantor model (Jukes and Cantor 1969). Trees with the highest loglikelihoods (- 310.50, - 409.01, and - 1505.68 for the ITS, $28 S$, and $18 S$ gene, respectively) are shown in Fig. 1. The percentage of trees in which the associated taxa clustered together is shown next to the branches. Initial trees for the heuristic search were obtained automatically by applying Neighbor-Join and BioNJ algorithms to a matrix of pairwise distances estimated using the maximum composite likelihood (MCL) approach and then selecting the topology with superior log likelihood value. The trees were drawn to scale, with branch lengths measured in the number of substitutions per site. The analysis involved 18, 15, and 18 nucleotide sequences for the ITS, 28S, and $18 S$ taxonomic study, respectively. Codon positions included were $1 \mathrm{st}+2 \mathrm{nd}+3 \mathrm{rd}+$ noncoding. All positions containing gaps and missing data were eliminated. There were 152, 131, and 412 positions in the final dataset of the ITS, $28 S$, and $18 S$ taxonomic studies, respectively.

The multiple alignments of an 819-bp segment of the ITS gene for 18 taxa showed 559, 455, 437, and 17 conserved, variable, singleton, and parsimony-informative sites, respectively. The phylogenetic tree showed that the $H$. zealandica strain ETL (MH443371) formed a polyphyletic group with other Heterorhabditis isolates, and it is closest to $H$. zealandica strain Bartow (GU174009) (Fig. 1a). The 614-bp segment of the $28 S$ gene for 15 taxa showed 818, 161, 77, and 75 conserved, variable, singleton, and parsimony-informative sites, respectively. The phylogenetic tree indicated that the strain ETL (MH443381) was closest to $H$. zealandica (AM039761) (Fig. 1b) in a polyphyletic group among other Heterorhabditis species (Fig. 1b), whereas the 515bp segment of the $18 S$ gene for 18 taxa showed 415, 640, 463, and 96 conserved, variable, singleton, and parsimony-informative sites, respectively. The phylogenetic tree indicated that strain ETL (MN341010) was closest to Heterorhabditis sp. EPNKU59 (MG742141) (Fig. 1c) in a polyphyletic group among other Heterorhabditis isolates (Fig. 1c).

The $18 S$ rRNA sequence was detected to be suboptimal at resolving the taxonomic conflicts at species level, as it had fewer taxon, which is reported to evolve at a slower rate (Stock 2009). Reportedly, this is because of its slow evolutionary rate (Stock 2009) and has been used to differentiate the monophyletic origins of nematode groups (Peat et al. 2009). The 5.8S rRNA region of the ITS is short and highly conserved than the ITS-1 and ITS-2 regions (Stock 2009), but evolve more rapidly than the $18 S$ and $28 S$ genes. Thus, they are ideal (i) for the EPN taxonomic studies at species (population) levels and (ii) for population genetic studies (Stock 2009). The ITS-1 region is reportedly sufficient at differentiating species and assessing their evolutionary relationships, particularly among the Heterorhabditis spp. (Stock 2009; Peat et al. 2009). The $28 S$ rRNA varied more rapidly than the $18 S$ rRNA and had fewer positional ambiguities during alignment than ITS (Stock 2009). However, the 


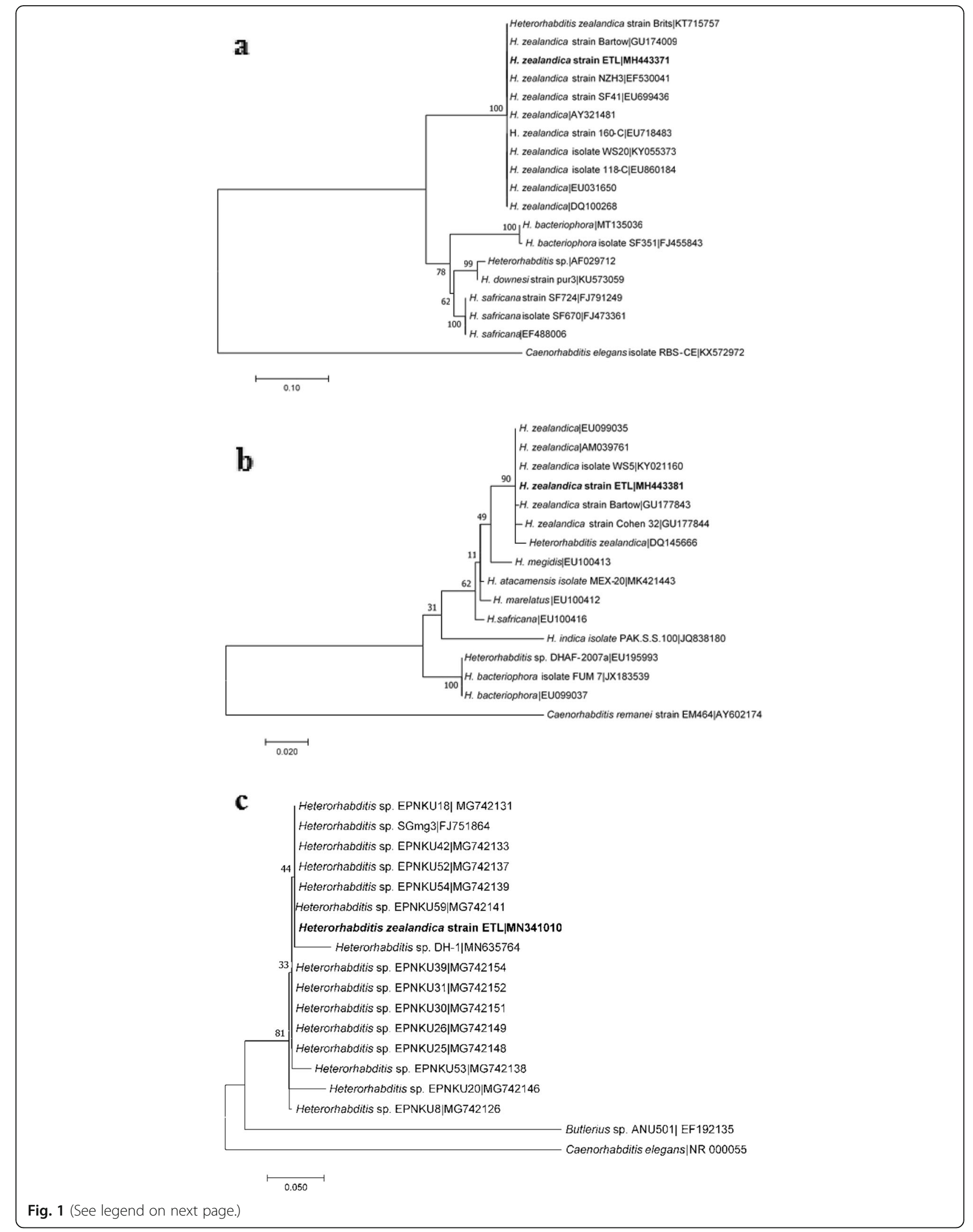


(See figure on previous page.)

Fig. 1 Maximum likelihood phylogenetic tree of Heterorhabditis zealandica strain ETL and its closest neighbors based on a the ITS region, Caenorhabditis elegans strain RBS-CE KX572972 was included as an out-group; b D2-D3 region of the 28S rRNA gene, C. remanei strain EM464 AY602174 was included as an out-group; and $\mathbf{c}$ the 18S rRNA gene, C. elegans NR_000055 was included as an out-group. The numbers on nodes indicate bootstrap values after 1000 replicates expressed in percentages

$28 S$ rRNA has been attested more informative and suitable for the assessment of phylogenetic relationships, delimitation of terminal taxa, and for diagnostic purposes among Steinernema spp. (Stock and Hunt 2005; Stock 2009).

\section{Entomopathogenic nematode pathogenicity test}

The EPN pathogenicity test was repeated $(4 \times)$, and a number of dead G. mellonella larvae (mean \pm RSD) 1.72 $\pm 0.5,2.75 \pm 0.5,3.5 \pm 0.5$, and $4 \pm 0(p 0.006)$ were collected daily after EPN application, respectively. The data are presented in Table 2. No statistical difference was found with the G. mellonella quadruplet EPN pathogenicity experiments. The scatter-gram and line of best fit were obtained from the time vs. mortality of larvae for each experiment (Fig. 2a). A coefficient of linearity $(r)$ of 0.95 was obtained for all replicated experiments. As for
G. mellonella, the number of dead T. mollitor larvae (mean \pm RSD) $1 \pm 0,2 \pm 0,2.75 \pm 0.5$, and $4 \pm 0(p>$ 0.001 ) were recorded at the 1st, 2nd, 3rd, and 4th day post-EPN application, respectively (Table 2 ). Again, a non-statistical difference was found. The scatter-gram and line of best fit (Fig. 2b) showed similar $r$ values (> $0.96)$ for all replicated experiments.

Heterorhabditis zealandica strain ETL was capable of infecting G. mellonella and T. mollitor within 24-96 h (Fig. 2a, b), which was within the criterion (5 days) for entomopathogenicity suggested by Dillman et al. (2012b). About $50 \%$ of the larvae population was killed within 24 and $48 \mathrm{~h}$ for G. mellonella and T. mollitor, respectively. After $96 \mathrm{~h}$, mortality reached $100 \%$ and the nematodes emerged from the cadaver 2-3 days after death. The color change of dead larvae observation (Fig. 2c) disclosed a biocontrol potential of $H$. zealandica strain

Table 2 Entomopathogenic nematode (EPN) pathogenicity against Galleria mellonella and Tenebrio mollitor larvae

\begin{tabular}{|c|c|c|c|c|c|c|c|c|c|}
\hline \multicolumn{10}{|c|}{ EPN pathogenicity test } \\
\hline \multicolumn{10}{|c|}{ 1) Galleria mellonella } \\
\hline & & \multicolumn{8}{|c|}{ Number of dead larvae } \\
\hline & & \multicolumn{2}{|l|}{ Day 1} & \multicolumn{2}{|l|}{ Day 2} & \multicolumn{2}{|l|}{ Day 3} & \multicolumn{2}{|l|}{ Day 4} \\
\hline \multirow[t]{4}{*}{ Time (day) } & Replicate 1 & \multicolumn{2}{|l|}{2} & \multicolumn{2}{|l|}{2} & \multicolumn{2}{|l|}{4} & \multicolumn{2}{|l|}{4} \\
\hline & Replicate 2 & \multicolumn{2}{|l|}{1} & \multicolumn{2}{|l|}{3} & \multicolumn{2}{|l|}{3} & \multicolumn{2}{|l|}{4} \\
\hline & Replicate 3 & \multicolumn{2}{|l|}{2} & \multicolumn{2}{|l|}{3} & \multicolumn{2}{|l|}{3} & \multicolumn{2}{|l|}{4} \\
\hline & Replicate 4 & \multicolumn{2}{|l|}{2} & \multicolumn{2}{|l|}{3} & \multicolumn{2}{|l|}{4} & \multicolumn{2}{|l|}{4} \\
\hline \multirow[t]{6}{*}{ Statistics } & Mean & \multicolumn{2}{|c|}{$1.75(50 \%)$} & \multicolumn{2}{|c|}{$2.75(\sim 75 \%)$} & \multicolumn{2}{|c|}{$3.5(87.50 \%)$} & \multicolumn{2}{|l|}{$4(100 \%)$} \\
\hline & RSD & \multicolumn{2}{|l|}{0.5} & \multicolumn{2}{|l|}{0.5} & \multicolumn{2}{|l|}{0.5} & 0 & \\
\hline & Std. error & 0.25 & & 0.25 & & 0.289 & & 0 & \\
\hline & $95 \%$ confidence interval & Lower & Upper & Lower & Upper & Lower & Upper & Lower & Upper \\
\hline & & 1.25 & 2 & 2.25 & 3 & 3 & 4 & 4 & 4 \\
\hline & $p$ value & 0.006 & & & & & & & \\
\hline 2) Tenebrio & & & & & & & & & \\
\hline Time (day) & Replicate 1 & 1 & & 2 & & 3 & & 4 & \\
\hline & Replicate 2 & 1 & & 2 & & 3 & & 4 & \\
\hline & Replicate 3 & 1 & & 2 & & 2 & & 4 & \\
\hline & Replicate 4 & 1 & & 2 & & 3 & & 4 & \\
\hline Statistics & Mean & $1(25 \%)$ & & $2(50 \%)$ & & 2.75 & & $4(100 \%)$ & \\
\hline & RSD & 0 & & 0 & & 0.5 & & 0 & \\
\hline & SEM & 0 & & 0 & & 0.25 & & 0 & \\
\hline & $95 \%$ confidence interval & Lower & Upper & Lower & Upper & Lower & Upper & Lower & Upper \\
\hline & & 1 & 1 & 2 & 2 & 2.25 & 3 & 4 & 4 \\
\hline & $p$ value & $<0.001$ & & & & & & & \\
\hline
\end{tabular}



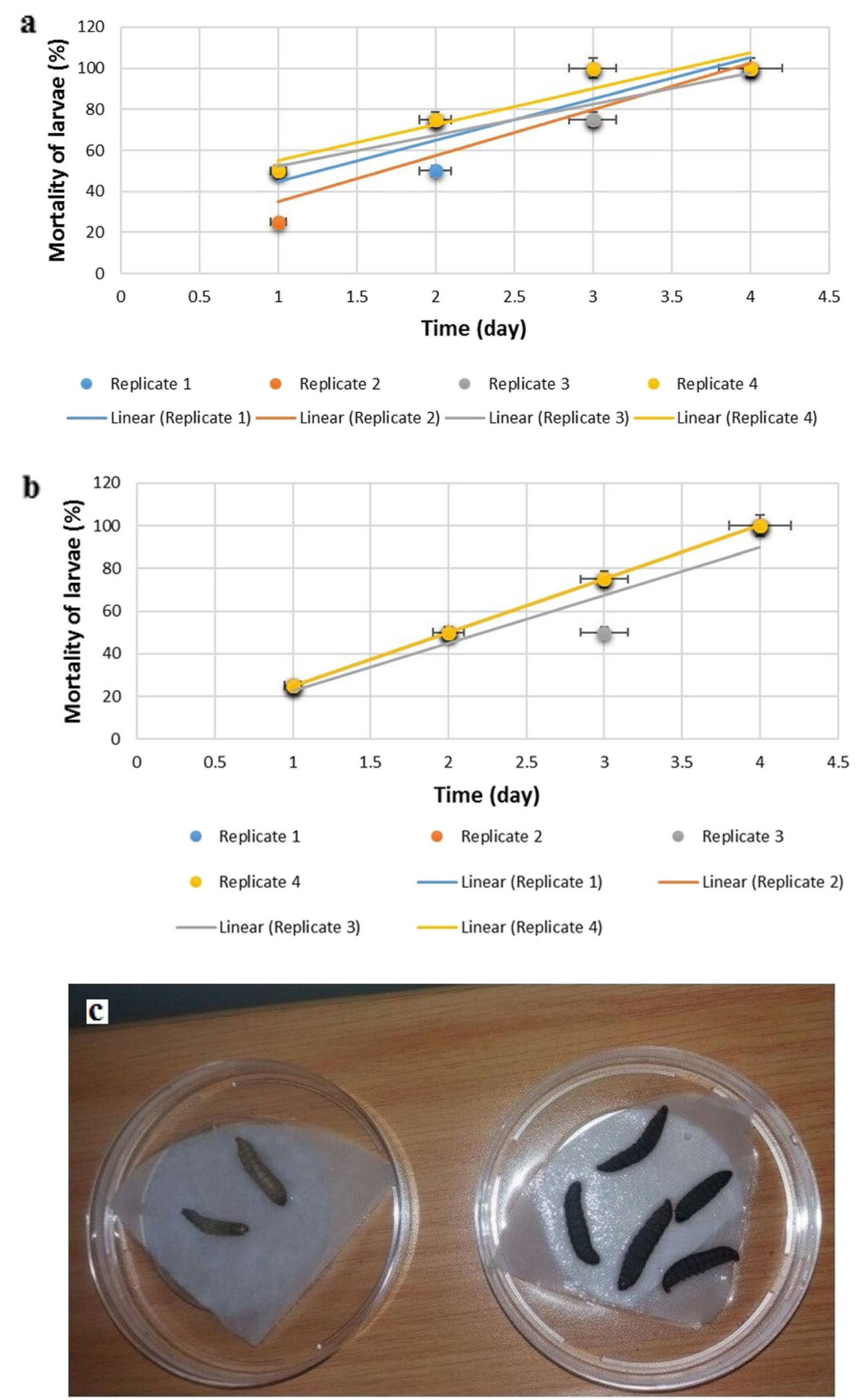

Fig. 2 Infectivity of Heterorhabditis zealandica strain ETL against both a Galleria mellonella and b Tenebrio mollitor larvae. c White-trap used to collect infective juveniles from larva cadavers, a Petri dish with distilled water, and G. mellonella larva on filter paper. Live G. mellonella larvae (left) versus dead $G$. mellonella larvae (right) 
ETL against insects. This could be due to synergetic effects of cell clumping, protease activities, crystal protein production, and/or anthraquinone production (pigmentation) by EPN symbiotic bacteria within insect cadavers (Eckstein and Heermann 2019). This is an interesting observation and it revealed a biocontrol potential of $H$. zealandica strain ETL against insects from the Lepidoptera and Coleoptera orders and possible use against other insects.

One approach to enhance the EPN efficiency in fields has been isolating EPN species from different areas that could display a significant behavioral and physiological adaptation ( $\mathrm{Lu}$ et al. 2016). The recovery of native $H$. zealandica strain ETL from the province of Limpopo, an unexplored region in South Africa, further demonstrates the richness of South African EPN fauna with biocontrol potential (Hatting and Malan 2017), suggesting further research and extensive sampling.

The species $H$. zealandica strain ETL was successfully characterized based on morphological characters of the IJ and based on its molecular sequences of three (ITS, $18 S$, and 28S) genetic markers. The usefulness of molecular data to distinguish these species was documented (Campos-Herrera 2015). The comparison of the ITS, $18 \mathrm{~S}$, and $28 \mathrm{~S} \mathrm{rDNA}$ sequences with available sequences of other described species indicated the isolate as an EPN isolate among the Heterorhabditis group. The phylogenetic analysis data to infer the relationships of the isolated strain with other Heterorhabditis found that it was in a polyphyletic clade with $100 \%$ support (Fig. 1c) and was placed closest to $H$. zealandica strain Bartow (GU174009) in the Heterorhabditis group (Fig. 1b) supported with 99.88 and $99 \%$ of similarities and query coverage of a 819-bp sequence. This was demonstrated by the $18 S$ rRNA sequence (Fig. 1c) and ITS rRNA sequence (Fig. 1a), respectively, while the $28 S$ rRNA sequence (Fig. 1b) provided more information on its proximity to strain Bartow (GU174009). Moreover, the $18 S$ rRNA sequence (Fig. 1c) revealed the proximity of strain ETL to other strains from Thailand, and other $H$. zealandica isolates recovered from Australia, Lithuania, New Zealand, Russia, and USA) confirm the widespread occurrence of these strains; although they have been rarely recovered in SA (Malan et al. 2011). Future surveys are needed to better assess the distribution of these strains in South Africa. Other H. zealandica strains isolated from neighboring provinces within South Africa (De Waal et al. 2018) such as Mpumalanga, KwaZuluNatal, Eastern Cape, and Western Cape provinces demonstrate a behavioral and physiological adaptation that could be beneficial for their bio-control potential. Strain ETL was lethal to G. mellonella and T. mollitor; infections occurred within 24-96 h. Fifty percent of the larvae population were killed within $24 \mathrm{~h}$ and $100 \%$ after $96 \mathrm{~h}$.

\section{Conclusion}

This is among the first documented record of species of EPNs isolated from the Limpopo Province of South Africa. It was identified as Heterorhabditis zealandica strain ETL and is a potential biocontrol agent against insects from the Lepidoptera and Coleoptera orders, thus indicating a potential use against other agricultural industry key insect pests.

\section{Supplementary information}

Supplementary information accompanies this paper at https://doi.org/10. 1186/s41938-020-00279-0.

Additional file 1: Figure S1. Morphological features of the isolate showing a tessellate pattern in anterior most region (a). Lateral field with two ridges (b). Prominent cuticular dorsal tooth present (c, d, and e).

\section{Abbreviations}

BLAST: Basic Local Alignment Search Tool; bp: Base-pairs(s); $\mathrm{CO}_{2}$ : Carbon dioxide; DNA: Deoxyribonucleic acid; EPN: Entomopathogenic nematode; EST: Expressed sequence tag; EtBr: Ethidium bromide; GPS: Global Positioning System; IJ: Infective juvenile; ITS: Internal transcribed spacer; LSU: Large subunit; MCL: Maximum composite likelihood; MEGA: Molecular Evolutionary Genetics Analysis; mRNA: Messenger RNA; MUSCLE: MUltiple Sequence Comparison by Log-Expectation; NCBI: National Center for Biotechnology Information; NTS: Non-transcribed spacer; PCR: Polymerase chain reaction; rDNA: Ribosomal DNA; RNA: Ribonucleic acid; rRNA: Ribosomal ribonucleic acid; RSD: Relative standard deviation; SA: South Africa; SEM: Scanning electron microscope; SSU: Small subunit; TBE: Tris base, boric acid, and ethylenediaminetetraacetic acid; USA: United States of America; V: Volt(s)

\section{Acknowledgements \\ The authors thank the University of Johannesburg Spectrum staff, for assistance with the electron microscope.}

\section{Authors' contributions}

LTE conducted the experiments, data collection, and data analysis and drafted the manuscript. S-DMH participated in the design of the study and supervised the project. The authors read and approved the final manuscript.

\section{Funding}

This work was funded by the South African National Research Foundation, Thuthuka grant number TTK170405225920. The funders had no role in the study design, data collection and analysis, decision to publish, or preparation of the manuscript.

\section{Availability of data and materials}

The datasets used and/or analyzed during the current study are available from the corresponding author on reasonable request.

Ethics approval and consent to participate

Not applicable.

\section{Consent for publication}

Not applicable.

\section{Competing interests}

The authors declare that they have no competing interests.

Received: 4 March 2020 Accepted: 3 June 2020

Published online: 22 June 2020

\section{References}

Adams BJ, Fodor A, Koppenhofer HS, Stackebrandt E, Stock SP, Klein MG (2006) Biodiversity and systematics of nematode-bacterium entomopathogens. Biol Control 37:32-49 
Azazy AM, Abdelall MFM, El-Sappagh IA, Khalil AEH (2018) Biological control of the onion thrips, Thrips tabaci Lindeman (Thysanoptera: Thripidae), in open fields using Egyptian entomopathogenic nematode isolates. Egypt J Biol Pest Co 28(1):1-6

Bedding R, Akhurst R (1975) A simple technique for the detection of insect parasitic rhabditid nematodes in soil. Nematologica 21(1):109-110

Campos-Herrera R (2015) Nematode pathogenesis of insects and other pests: ecology and applied technologies for sustainable plant and crop protection. Springer International Publishing, Switzerland

De Waal JY, Addiso MF, Malan AP (2018) Potential of Heterorhabditis zealandica (Rhabditida: Heterorhabditidae) for the control of codling moth, Cydia pomonella (Lepidoptera: Tortricidae) in semi-field trials under South African conditions. Int J Pest Manage 64(2):102-109 https://doi.org/10.1080/ 09670874.2017.1342149

Dillman AR, Chaston JM, Adams BJ, Ciche TA, Goodrich-Blair H, Stock SP, Sternberg PW (2012b) An entomopathogenic nematode by any other name. PLoS Pathog 8(3):el002527

Eckstein S, Heermann R (2019) Regulation of phenotypic switching and heterogeneity in Photorhabdus luminescens cell populations. J Mol Bio https://doi.org/10.1016/j.jmb.2019.04.015

Edgar RC (2004) MUSCLE: a multiple sequence alignment method with reduced time and space complexity. BMC Bioinformatics 5:113 https://doi.org/10. 1186/1471-2105-5-113

Glazer I, Lewis EE (2000) Bioassays for entomopathogenic nematodes. In: Navon A, Ascher KRS (eds) Bioassays of entomopathogenic microbes and nematodes. CABI, Wallingford, pp 229-245

Hall T (2005) BioEdit: biological sequence alignment editor for Win95/98/2 KNX, Last update 5/31/2005. Ibis Therapeutics, Carlsbad, CA 92008. Available on http://www.mbio.ncsu.edu/BioEdit/page2.html. Accessed on 11/09/2019.

Hatting JL, Malan AP (2017) Status of entomopathogenic nematodes in integrated pest management strategies in South Africa. In: Abd-Elgawad MMM, Askary TH, Coupland J (eds) Biocontrol agents: Entomopathogenic and slug parasitic nematodes. CABI, Switzerland, pp 409-428

Joyce SA, Reid A, Driver F, Curran J (1994) Application of polymerase chain reaction $(P C R)$ methods to the identification of entomopathogenic nematodes. In: Burnell AM, Ehlers RU, Massob JP (eds) Genetics of entomopathogenic nematodes-bacterium complexes. European Commission, Luxembourg, pp 178-187

Jukes TH, Cantor CR (1969) Evolution of protein molecules. In: Munro HN (ed) Mammalian Protein Metabolism. Academic Press, New York, pp 21-132

Kaya HK, Stock SP (1997) Techniques in insect nematology. In: Lacey L (ed) Manual of techniques in insect pathology. Academic Press, San Diego, pp 281-324

Kumar S, Stecher G, Tamura K (2016) MEGA7: molecular evolutionary genetics analysis version 7.0 for bigger datasets. Mol Biol Evol 33:1870-1874

Lu D, Baiocchi T, Dillman AR (2016) Genomics of entomopathogenic nematodes and implications for pest control. Trends Parasitol 32(8):588-598

Malan AP, Ferreira T (2017) Entomopathogenic nematodes. In: Fourie H, Spaull W, Jones RK, Daneel MS, De Waele D (eds) Nematology in South Africa: a view from the 21 st century. Springer International Publishing, Switzerland, pp 459-480

Malan AP, Knoetze R, Moore SD (2011) Isolation and identification of entomopathogenic nematodes from citrus orchards in South Africa and their biocontrol potential against false codling moth. J Invertebr Pathol 108:115125 https://doi.org/10.1016/j.jip.2011.07.006

Nguyen K, Hunt D (2007) Entomopathogenic nematodes: systematics, phylogeny and bacterial symbionts, vol 7. Nematology Monographs \& Perspectives: Brill

Nguyen KB, Maruniak J, Adams JB (2001) Diagnostic and phylogenetic utility of the rDNA internal transcribed spacer sequences of Steinernema. J Nematol 33:73-82

Peat SM, Hyman BC, Adams BJ (2009) Phylogenetics and population genetics of entomopathogenic and insect-parasitic nematodes. In: Stock P, Vandenberg J, Glazer I, Boemare N (eds) Insect pathogens. Molecular approaches and techniques. CABI, Oxfordshire, pp 166-184

Ruan W-b, Shapiro-llan D, Lewis EE, Kaplan F, Alborn H, X-hui G, Schliekelman P (2018) Movement patterns in entomopathogenic nematodes: continuous vs. temporal. J Invertebr Pathol 151:137-143

Stock SP (2009) Molecular approaches and the taxonomy of insect-parasitic and pathogenic nematodes. In: Stock P, Vandenberg J, Glazer I, Boemare N (eds) Insect pathogens. Molecular approaches and techniques. CABI, Oxfordshire, pp 71-94
Stock SP, Hunt DJ (2005) Nematode morphology and systematics. In: Grewal PS, Ehlers RU, Shapiro-llan DI (eds) Nematodes as Biological Control Agents. CABI, Wallingford, pp 3-43

Subbotin SA, Sturhan D, Chizhov VN, Vovlas N, Baldwin JG (2006) Phylogenetic analysis of Tylenchida Thorne, 1949 as inferred from D2 and D3 expansion fragments of the 28S rRNA gene sequences. Nematology 8:455-474

Torres-Barragan A, Suazo A, Buhler WG, Cardoza YJ (2011) Studies on the entomophathogenicity and bacterial associates of the nematode Oscheius carolinensis. Biol Control 59:123-129

Vovlas N, Landa BB, Liebana G, Handoo ZA, Subbotin SA, Castillo P (2006) Characterization of the cystoid nematode Meloidoderita kirjanovae (Nemata: Sphaeronematidae) from Southern Italy. J Nematol 38:376-382

White G (1927) A method for obtaining invective nematode larvae from culture. Science (Washington) 66:302-303

\section{Publisher's Note}

Springer Nature remains neutral with regard to jurisdictional claims in published maps and institutional affiliations.

\section{Submit your manuscript to a SpringerOpen ${ }^{\circ}$ journal and benefit from:}

- Convenient online submission

- Rigorous peer review

- Open access: articles freely available online

High visibility within the field

- Retaining the copyright to your article

Submit your next manuscript at $\boldsymbol{\nabla}$ springeropen.com 